\title{
Modelling Soil Organic Carbon Changes Under Different Maize Cropping Scenarios for Cellulosic Ethanol in Europe
}

\author{
E. Lugato • A. Jones
}

Published online: 2 October 2014

(C) The Author(s) 2014. This article is published with open access at Springerlink.com

\begin{abstract}
The utilization of crop residues in the production of second-generation biofuels has the potential to boost the bioenergy sector without affecting food commodity prices. However, policies leading to large-scale biomass removal should carefully balance the consequences, both environmental and in terms of emissions, on soil organic carbon (SOC) stocks depletion. Using a recently developed simulation platform, SOC changes were estimated at European level (EU + candidate and potential candidate countries) under two scenarios of low (R30) and high (R90) maize stover removal for cellulosic ethanol production (i.e. 30 and $90 \%$ of stover removal, respectively). Additionally, mitigation practices for SOC preservation, namely the introduction of a ryegrass cover crop (R90_C) and biodigestate return to soil (R90_B), were explored under the highest rate of stover removal. The results showed that 15.3 to $50.6 \mathrm{Mt}^{\text {year }}{ }^{-1}$ of stover (dry matter) would be potentially available for ethanol production under the lower and high removal rates considered. However, largescale exploitation of maize residues will lead to a SOC depletion corresponding to $39.7-135.4 \mathrm{Mt} \mathrm{CO}_{2}$ eq. by 2020 (under $\mathrm{R} 30$ and R90, respectively) with greater losses in the long term. In particular, every tonne of $\mathrm{C}$ residue converted to bioethanol was predicted to have an additional impact on SOC loss almost ranging from 0.2 to $0.5 \mathrm{CO}_{2}$ eq. $\mathrm{ha}^{-1}$ year $^{-1}$, considering a continuous biofuel scenario by
\end{abstract}

The views expressed in this paper are purely those of the writers and may not in any circumstances be regarded as stating an official position of the European Commission.

Electronic supplementary material The online version of this article (doi:10.1007/s12155-014-9529-2) contains supplementary material, which is available to authorized users.

E. Lugato $(\bowtie) \cdot$ A. Jones

European Commission, Joint Research Centre, Institute for

Environment and Sustainability, Via E. Fermi, 2749, 21027 Ispra,

VA, Italy

e-mail: emanuele.lugato@jrc.ec.europa.eu
2050. The mitigation practices evaluated could more than halve SOC losses compared to R90, but not totally offsetting the negative soil $\mathrm{C}$ balance. There is a pressing need to design policies at EU level for optimum maize biofuel cultivations that will preserve the current SOC stock or even generate C credits.

Keywords Soil organic carbon · Maize stover $\cdot$ Biofuel $\cdot$ Crop residues $\cdot$ Modelling

\section{Introduction}

One of the goals of the European Union (EU) climate and energy package, known as the "20-20-20" targets [1], is to raise the share of energy production from renewable resources to $20 \%$ by 2020 . Under this commitment, the conversion of land to bioenergy and biofuel crops has started to increase rapidly and is expected to continue, since an additional $20 \mathrm{Mha}$ is predicted to be required across Europe to support the bioenergy share by 2020 [2]. Annual food crops (i.e. oilseed rape, sugar beet, maize) provide more than $70 \%$ of the current EU bioenergy production, leading to serious concerns about the possibility of reduced food supply and neutrality of greenhouse gas (GHG) budget with regards to fossil fuels [3].

To overcome these limitations, development has focused on the production of second-generation biofuels that enables the transformation of lignocellulose material such as organic waste derived from perennial crops (e.g. Miscanhtus) or crop residues into biofuels. These technologies are still under development, but initial results are promising, especially if the co-product of annual food crops can be used. In this context, the use of maize stover for ethanol production, instead of the grain or the entire plant, would not alter the food market prices while at the same time be environmental neutral or negative in 
terms of GHG budget (emissions are proportionally allocated to co-product in life cycle assessment (LCA) analysis). However, one aspect that is not often properly considered in the production of biofuels is the depletion of soil organic carbon (SOC) levels that may occur by removing crop residues (and hence carbon input) from cultivated fields [4-6].

There is scientific agreement that lower carbon inputs have a negative consequence on SOC stock [7], but the effects of a potential bioenergy policy at European scale are still uncertain due to the variations in pedo-climatic conditions and the agricultural systems that need to be assessed. Some indications of possible SOC changes to due to residues harvest from biofuel crops come from both laboratory and field experiments. The former, for instance, reported a higher SOC decomposition (e.g. priming) by an average of $16 \%$ when labelled maize residues where removed from incubated soil jars [8]. Analysing data from field experiments, mostly in the USA [5], showed that a corn residue harvest of 25-100\% removal consistently resulted in SOC losses averaging 3$8 \mathrm{Mg} \mathrm{ha}^{-1}$ in the top 30-cm soil layer. In Ontario, due to the government commitment in shifting from coal to bioenergy sources of energy, sustainable residue removal rates were calculated with the aim of preserving existing SOC levels [9]. In Europe, despite the ambitious targets of the bioenergy sector, the large-scale impact of crop residues exploitation on SOC stock is still lacking. This may represent a contradiction in EU policy since the Common Agricultural Policy (CAP) for 2014-2020 aims to maintain soil organic matter levels through Good Agricultural and Environmental Condition (GAEC) schemes [10]. In addition to SOC sequestration, crop residues remaining on agricultural fields contribute to numerous ecosystem services that include nutrient cycling, control of water balance and erosion and crop production [11, 12]. The depletion of the SOC pool may also affect the GHG saving since $\mathrm{C}$ of photosynthetic origin in biofuel may be offset by net $\mathrm{CO}_{2}$ soil emissions; in fact, $\mathrm{EU}$ policy requires that biofuel from energy crops saves $35 \%$ of GHG compared to fossil fuels and even more in the future when the share of renewable energy will be targeted to reach at least $27 \%$ of the EU's energy consumption by 2030 [13].

The application of process-based models at large scales is a promising approach to explore bioenergy scenarios since such models are able to simulate water, carbon and nitrogen dynamics and crop growth in interaction with agricultural management practices [14]. Furthermore, inter-model comparisons have demonstrated that widely used models (e.g. Century, DNDC) can simulate accurately the effects on soil carbon due to crop residue removal [15].

Using a recently developed simulation platform for assessing the SOC stock in European agricultural soils [16], scenarios were run involving the utilization of maize residues for biofuel use. The aims were (1) to provide a spatially detailed assessment of SOC change due to maize stover exploitation and (2) to test alternative management scenarios aiming at mitigate the SOC depletion.

\section{Material and Methods}

This study was done using a recently developed simulation platform [16], coupling the well-known Century agroecosystem model [17] with several spatial and numerical databases at European level (EU + Serbia, Bosnia and Herzegovina, Montenegro, Albania, Former Yugoslav Republic of Macedonia and Norway). A comprehensive description of input data management, model structure and scenarios simulated is given in the following paragraphs, referring to Lugato et al. [16] for specific details.

\section{Model}

Century is a process-based model designed to simulate carbon (C), nitrogen (N), phosphorous (P) and sulphur (S) dynamics in natural or cultivated systems, using a monthly time step [17]. The soil organic matter sub-model includes three SOC pools, namely active, slow and passive, along with two fresh residue pools, structural and metabolic, each with a different turnover rate. Soil temperature and moisture, soil texture and cultivation practices have different effects on these rates. The model is also able to simulate the water balance, using a weekly time step, while a suite of simple plant growth models are included to simulate $\mathrm{C}, \mathrm{N}, \mathrm{P}$ and $\mathrm{S}$ dynamics of crops, grasses and trees. For this study, the model was run with the coupled C-N sub-models.

In the model application, all the coefficients controlling the decomposition kinetics of different SOC pools were left unchanged. Only site-specific inputs as soil characteristics, climatic data, crop rotation and management practices were implemented, as describe below. The model was previously tested by the principal author in long-term experiments located in northern Italy $[18,19]$, one of the most intensive European agricultural areas where maize is a dominant crop. Some additional information of the calibration and validation process, in particular regarding crop productivity, is reported as Supplementary Material (SM).

Moreover, the model uncertainty in estimating the current SOC content at European level was below $36 \%$ in half of the administrative regions (NUTS level 2) considered, as detailed in Lugato et al. [16]

\section{Input Data sets}

Soil data used by the model were derived from the European Soil Database (ESDB) available at the European Soil Data Centre (ESDAC, http://eusoils.jrc.ec.europa.eu/library/esdac/ esdac_access2.cfm) [20]. The properties considered for the 
topsoil layer $(0-30 \mathrm{~cm})$ included soil texture, bulk density, $\mathrm{pH}$, drainage class and rock content. Although Century has a simple water bucket model, the hydraulic properties (field capacity and wilting point) were estimated using a pedotransfer rule [21]. These two parameters were corrected for the presence of rock according to the factor: $\left[1-\left(R_{\mathrm{v}} / 100\right)\right]$, where $R_{\mathrm{v}}$ is the rock fragment content by volume. Data on soil depth or the presence of an impediment layer, derived from the ESDB, were used to define the bottom boundary layer.

Climate data were taken from a $10^{\prime} \times 10^{\prime}$ cell data set provided by the Climate Research Unit, University of East Anglia, UK (http://www.cru.uea.ac.uk/cru/data/hrg/) [22]. Monthly values of maximum and minimum temperature and precipitation were provided for the period 1900-2000, based on interpolated observed data. For the period 2000-2100, values were obtained from four different global climate models (GCMs) forced by four Intergovernmental Panel on Climate Change (IPCC) $\mathrm{CO}_{2}$ emissions scenarios, as reported in the Special Report on Emissions Scenarios (SRES) [23]. For the purpose of this study, two contrasting scenarios, HadCM3-A1FI ('world markets-fossil fuel intensive') and PCM-B1 ('global sustainability'), were selected as they encompass a wide range of climatic variations, the former is more extreme and the latter is more conservative. The Century model can simulate the effects of increasing atmospheric $\mathrm{CO}_{2}$ concentration, considering (1) the increase of net primary productivity (NPP) with a different response for $\mathrm{C} 3$ and $\mathrm{C} 4$ plant species, (2) the transpiration reduction which is supposed to happen in relation to a decrease in stomatal conductance and (3) the $\mathrm{C} / \mathrm{N}$ and shoot/root ratio change of grasses and crops. A linear growth rates in $\mathrm{CO}_{2}$ concentration to reach 954 ppmv for the A1FI scenario and 540 ppmv for the B1 scenario was assumed for 2100 [23].

Soil and climate layers were overlaid to identify homogenous soil-climate territorial units. The spatial extension of agricultural land use was derived from the Corine Land Cover (CLC) 2000-2006 databases (http://www.eea.europa. eu/publications/COR0-landcover). Each homogenous soilclimate unit previously identified was then overlaid with the land cover data (CLC), and the areas (ha) for the specific crop categories (arable, rice, vineyard, olive, orchard, pasture and complex systems) were calculated within each territorial unit.

Crop distributions within the arable class were calculated according to statistics from the EU Statistical Office (Eurostat) on the basis of crop production areas for NUTS2 regions (http://epp.eurostat.ec.europa.eu/portal/page/portal/agri environmental indicators/data/database). When building the crop rotations to be simulated, space was substituted by time, hypothesising a 4-year rotation in which each crop occupies $25 \%$ of the time (thus equivalent to $25 \%$ of the space). Each crop of the 4-year rotation was then allocated according to the relative distribution data from the Eurostat statistics, adopting some approximation rules based on the proximity to the class limit. The schedule files for 18 arable or fodder crops (barley, wheat, maize grain, silage maize, soybean, sugar beet, sunflower, tobacco, ryegrass, alfalfa, rice, pulses, oilseed, rape, cotton, potato, tobacco, rice) were created. Management practices, including fertilisation, tillage and irrigation, were implemented specifically for each crop, gathering information from several sources (see [16]).

For the purpose of this study, territorial combinations $(22,831$ in total) containing the grain maize in the crop rotation were selected, the residues of which were assumed to be incorporated into the soil according to the business as usual (BAU) management hypothesis. Due to the approximation rule adopted, grain maize was not included in the rotation programme when only marginal areas were covered at NUTS2 level. The model simulated a grain maize area of 9.4 (EU27) against 9.0 Mha from Eurostat and 10.7 against 10.2 Mha (FAOSTAT, www.faostat.fao.org) when all national states were considered (EU + Serbia, Bosnia and Herzegovina, Montenegro, Albania, Former Yugoslav Republic of Macedonia); relative differences in area coverage were less than $5 \%$.

\section{Model Spin-up and Scenario Analysis}

The Century model was initialised through a series of management sequences encompassing the main agricultural technological stages of the last 2,000 years, until the actual management representing the BAU scenario. The hypothesis under the BAU is that maize stover is left on the field and incorporated by the successive tillage operation, as commonly done in Europe. The BAU conditions were then projected forward on the basis of two climatic scenarios from 2013 until 2100 as well as the following biofuel scenarios:

- R30: removal of $30 \%$ of grain maize residues

- R90: removal of $90 \%$ of grain maize residues

- R90_C: removal of $90 \%$ of grain maize residues with the insertion of a cover crop preceding the maize in the rotation schemes; specifically, ryegrass planted in November and all biomass incorporated (i.e. green manure) in March before sowing the maize. No nitrogen fertilisation was applied to the cover crop.

- R90_B: removal of $90 \%$ of maize grain residues and biodigestate return to soil. biofuel processing cogenerates an organic non-hydrolysable by-product commonly known as non-fermentable lignin. This by-product was assimilated as a manure input in the model, considering a $\mathrm{C}$ yield of $43 \%$ of the original feedstock (maize stover), a $\mathrm{C} / \mathrm{N}$ ratio of 30 and a lignin fraction equal to 0.59 [24].

The resulting SOC changes were expressed as differences with respect to the BAU baseline for different time frames (every 10 years between 2020 and 2100), hypothesising a full 
application of the four scenarios to all arable land. The resulting net changes compared with no residue removal (as assumed in the BAU) are in line with the consequential LCA, generally best suited for policy analysis when environmental impacts due to an alternative use of a product should be evaluated [25].

\section{Results}

The total amount of dry matter annually available by 2100 (Fig. 1) was calculated, considering a $\mathrm{C}$ concentration of $42 \%$ in maize stover. At European level, the removal of 30 and $90 \%$ of maize residues would lead to the potential conversion of 15.3 and $50.6 \mathrm{Mt} \mathrm{year}^{-1}$ of dry matter for ethanol production. These scenarios showed the technical potential (i.e. the full conversion of grain maize areas to removal of residues) for the largest maize producers such as France, Romania and Italy.

A large-scale removal of maize residues resulted in SOC losses approaching $0.5 \mathrm{t} \mathrm{C} \mathrm{ha}^{-1}$ by 2020 , under R30 scenario (Fig. 2). In areas more specialized in maize cultivation, where this crop occurred in high proportion within the rotation (i.e.

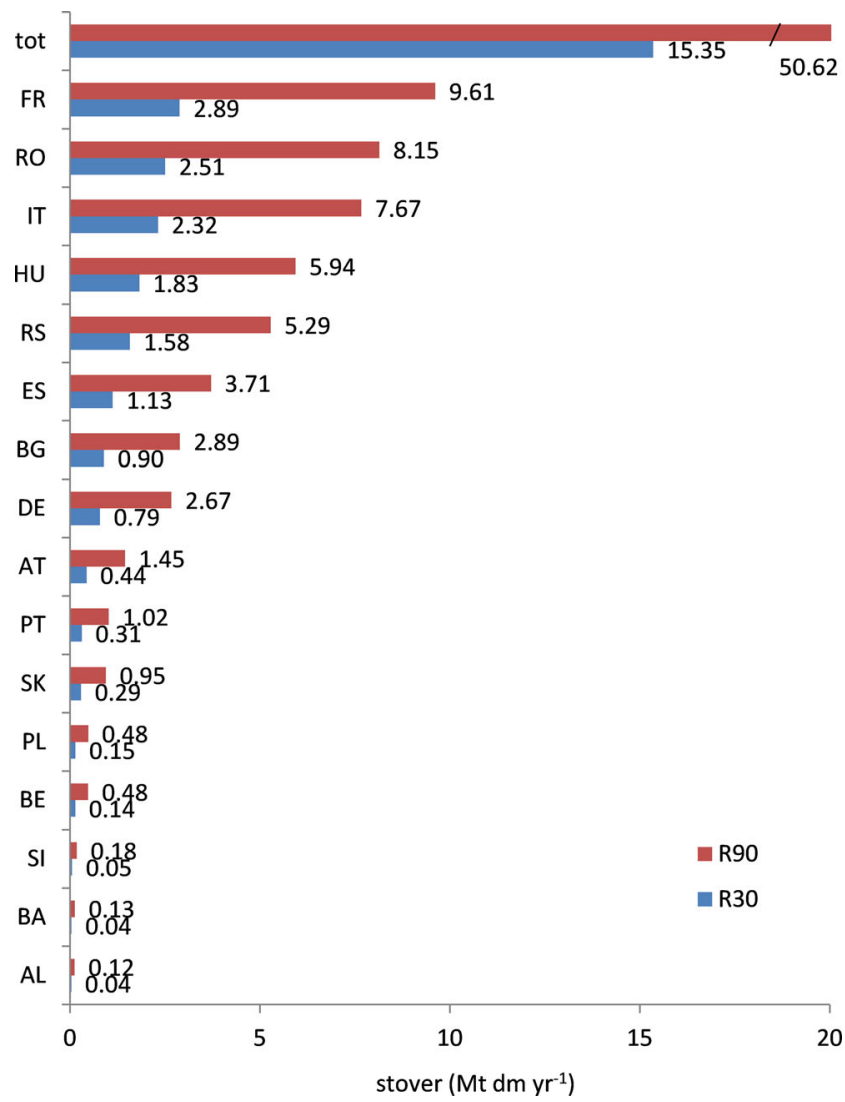

Fig. 1 Total amount of dry matter annually available (Mt d.m. year ${ }^{-1}$ ) by 2100 for ethanol production, considering the R30 and R90 rate of maize stover removal for the different European countries eastern France, northern Italy and Serbia), SOC changes ranged from -0.5 to -1.0 t $\mathrm{C} \mathrm{ha}{ }^{-1}$. Under the $\mathrm{R} 90$ scenario, those areas showed SOC losses greater than $1.5 \mathrm{t} \mathrm{C} \mathrm{ha}^{-1}$ in 0 $30 \mathrm{~cm}$ soil depth, while in the remainder of the arable land, changes between -0.5 and $-1.5 \mathrm{t} \mathrm{Cha}^{-1}$ were observed.

The incorporation of a cover crop preceding the maize (R90_C) resulted in lower SOC losses with respect to R90, especially in northern Portugal and France (Fig. 2). The mitigation effect of the R90_B scenario was higher than that of R90_C, with SOC losses lower than $0.5 \mathrm{t} \mathrm{C} \mathrm{ha}^{-1}$ in general.

Moderate stover exploitations (R30) resulted in modest losses of SOC, also in the medium-term perspective (2050, Fig. 3). Under the high removal rate, the biodigestate incorporation consistently mitigated the SOC depletion, since the model simulated comparable values between R90_B and R30.

Regarding the cumulated values (Fig. 4), SOC changes were $-0.011,-0.012,-0.021$ and $-0.037 \mathrm{Gt}$ of C (corresponding to emissions of 39.7, 45.0, 77.6 and $135.4 \mathrm{Mt}$ of $\mathrm{CO}_{2}$ eq.) by 2020 in R30, R90_B, R90_C and R90, respectively. The trends were more rapid in the R90 and R90_C scenarios, while the other scenarios were close to a steady state after 50 years. Despite the variability associated to climate change being higher in the last 40 years of the simulation period, the average SOC changes values by 2100 were all negative, ranging between -0.032 and -0.104 Gt of $\mathrm{C}$ (corresponding to emission of 116.2 and $383 \mathrm{Mt}$ of $\mathrm{CO}_{2}$ eq.).

To give some indication of the potential impact of stover removal in a LCA analysis, SOC changes under R90 scenario were divided by the amount of $\mathrm{C}$ stover removed (Fig. 5). Every tonne of $\mathrm{C}$ residue converted to bioethanol was predicted to have an additional impact ranging from 0.2 to $0.5 \mathrm{CO}_{2}$ eq. ha ${ }^{-1}$ year $^{-1}$, considering a continuous biofuel scenario by 2050. The effects were strongly heterogeneous in space, highlighting the necessity to consider both the environmental and management conditions of the cropping systems involved.

\section{Discussion}

The conversion of maize residues into bioethanol appears to be a promising strategy towards a low-carbon economy in Europe. However, the impact on SOC stocks is undoubtedly a key aspect, which may affect the sustainability of the system both in terms of GHG budget, soil quality and ecosystem services. Some case studies in the USA have reported an environmental GHG benefit of no-till maize- and stover maize-derived ethanol compared to gasoline-fueled vehicles by LCA analysis [26, 27]. In the first case, the no-till adoption was estimated to sequester $377-681 \mathrm{~kg} \mathrm{C}^{-1}$ year $^{-1}$ while, in the second, no SOC variation was accounted for Whitman et al. [28], conducting a life cycle assessment of corn stover production for cellulosic ethanol in Quebec, showing that soil 
R30

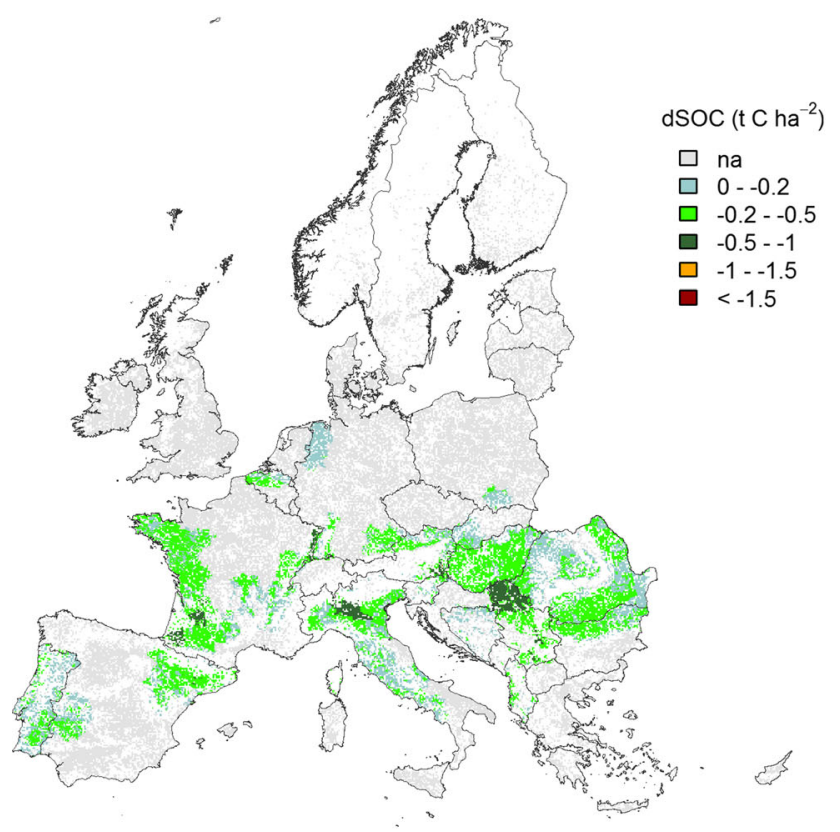

R90_C

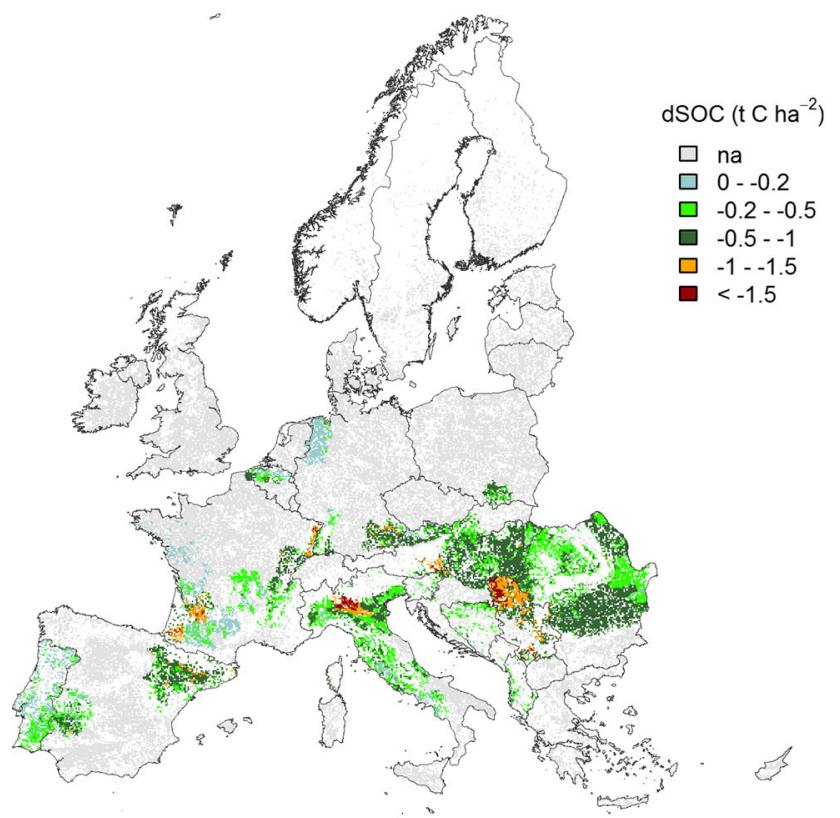

R90

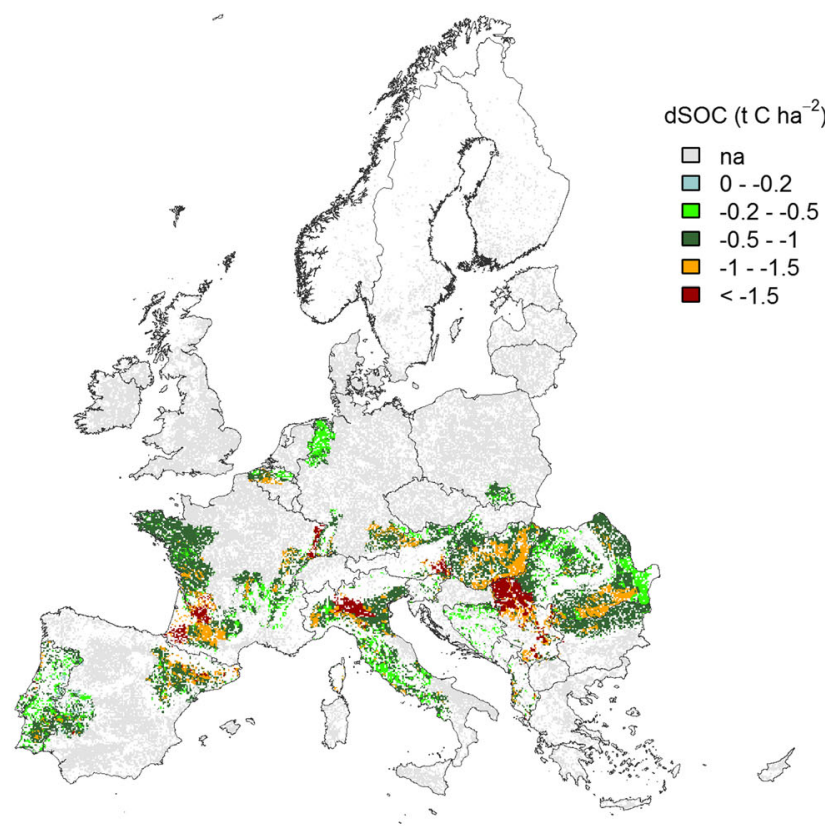

R90_B

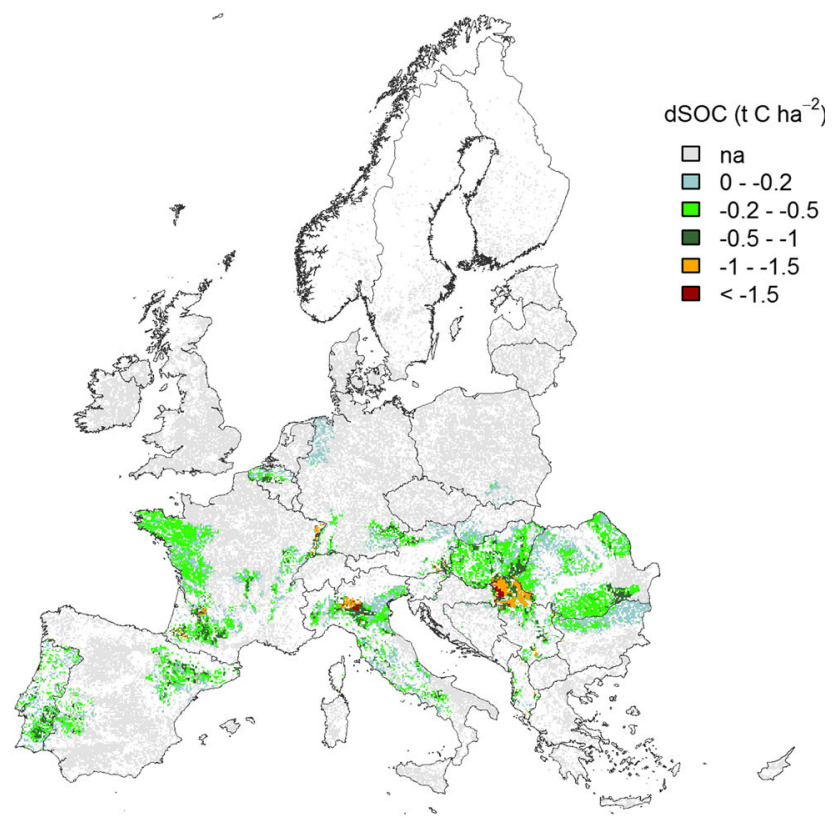

Fig. 2 SOC stock change ( $\mathrm{t} \mathrm{Cha}^{-1}$ in the 0-30 $\mathrm{cm}$ layer) by 2020 in the four maize biofuel scenarios simulated: $\mathrm{R} 30$ (removal of $30 \%$ of maize stover), R90 (removal of $90 \%$ of maize stover), R90_C (incorporation of a cover crop preceding maize) and R90_B (biodigestate return to soil)

carbon dynamics are a major contributor to the total GHG impact, even if this strong sensitivity was affected by the use of IPCC factors.

At EU level, the Renewable Energy Directive incentivises the use of non-food and land biomass resources by awarding them financial credits and assigning them a zero GHG cost.
However, Whittaker et al. [28] remarked that the inclusion of SOC changes in LCA analysis may reduce GHG emission savings by $133 \%$ if the effect of cereal straw removal is properly taken into account. In a recent paper, Liska et al. [29] noted that life cycle emissions will probably exceed the US legislative mandate of $60 \%$ reduction in GHG emissions 
R30

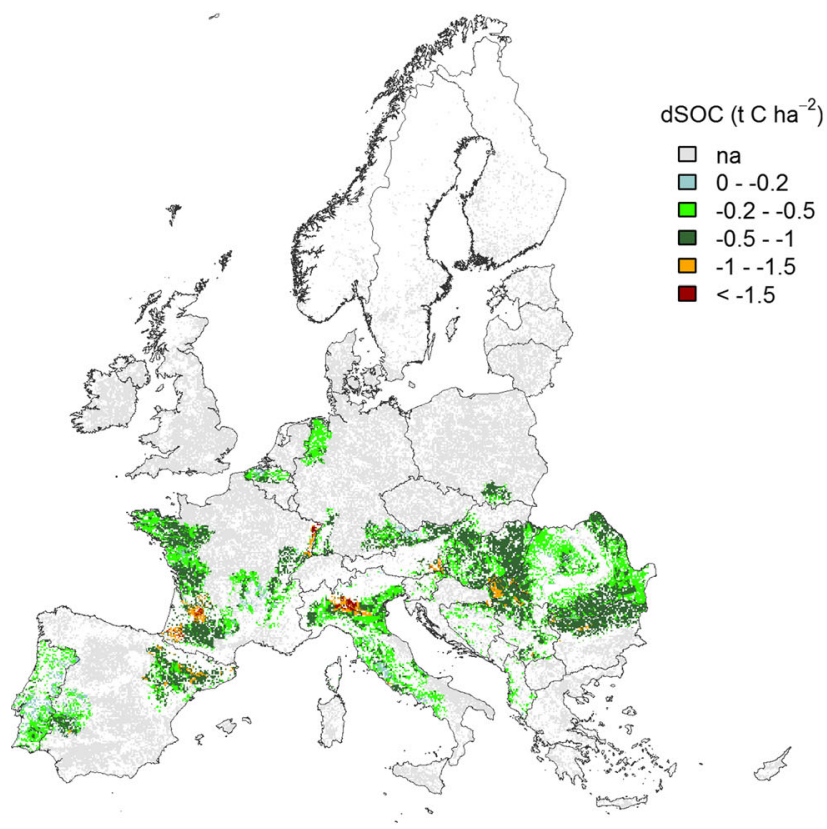

R90_C

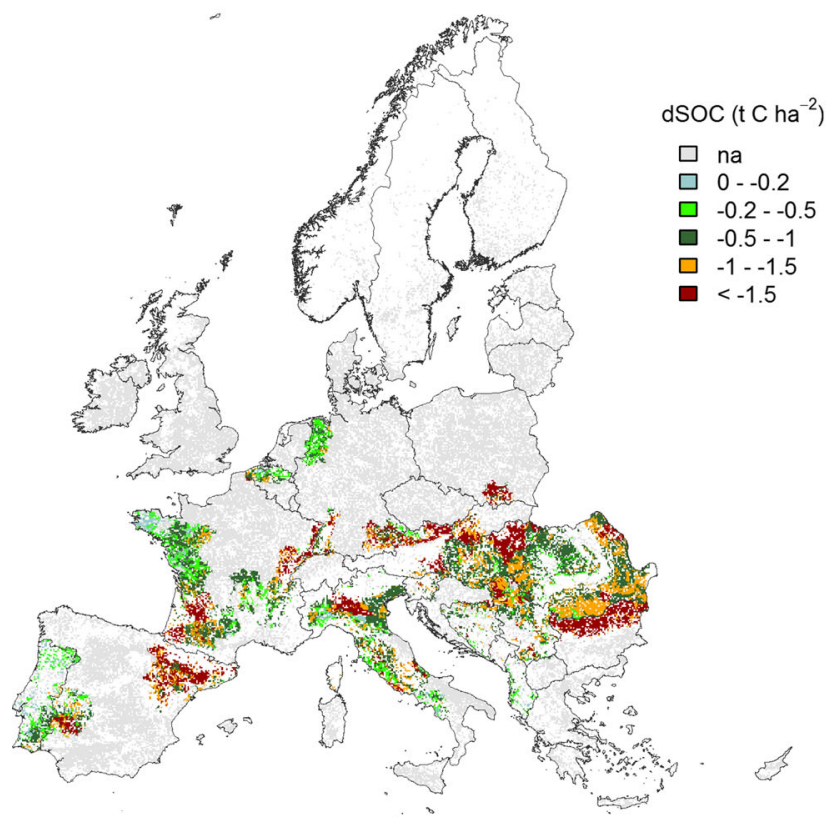

R90

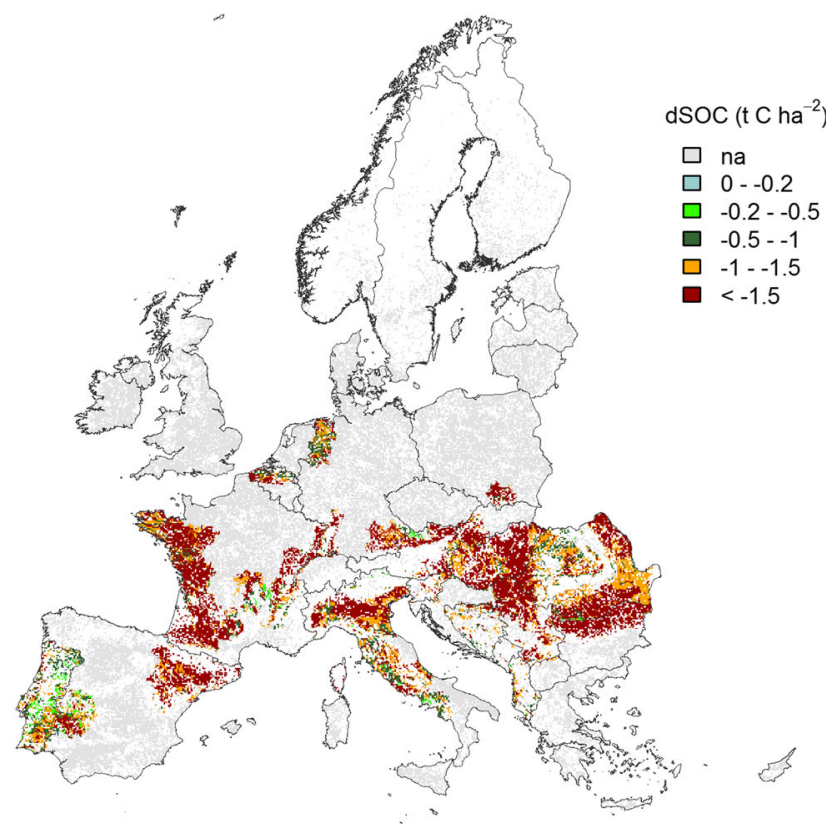

R90_B

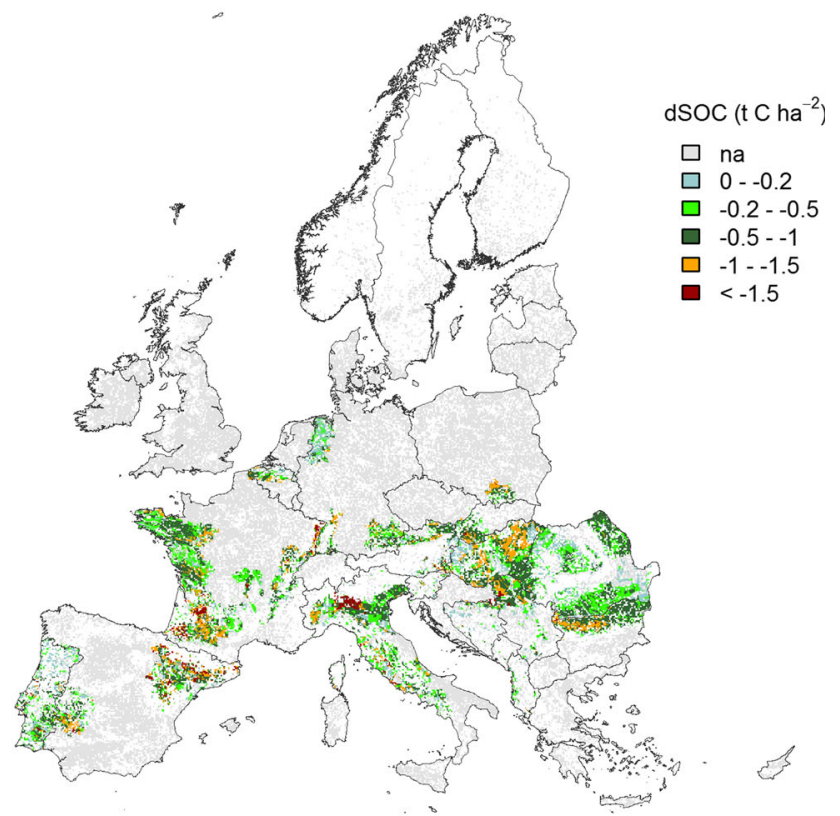

Fig. 3 SOC stock change ( $\mathrm{t} \mathrm{Cha}^{-1}$ in the $0-30 \mathrm{~cm}$ layer) by 2050 in the four maize biofuel scenarios simulated: $\mathrm{R} 30$ (removal of $30 \%$ of maize stover), R90 (removal of $90 \%$ of maize stover), R90_C (incorporation of a cover crop preceding maize) and R90_B (biodigestate return to soil)

compared with gasoline (under the next US biofuel targets), if $6 \mathrm{t} \mathrm{ha}^{-1}$ year $^{-1}$ of maize stover will be removed over 5 to 10 years. Our results suggested that large-scale stover removal from conventional maize systems may have a significant impact at European level, since cumulated losses continuously increased from 0.03 to $0.1 \mathrm{Gt}$ of C by 2020 and 2100 , respectively (corresponding to emissions of 122 and $382 \mathrm{Mt}$ $\mathrm{CO}_{2}$ eq.). Moreover, according to a recent decision of the European Parliament and the European Council in May 2013 [30], the GHG accounting on cropland and grazing land management will be mandatory. This implies that SOC changes related to a different management of crop residues should 
Fig. 4 Cumulated SOC stock change (Gt of C) at pan-European level for different time frames. The blue line is the average of the two climatic scenarios. The changes are calculated as difference with BAU and the corresponding $95 \%$ confidence interval according to the error propagation: $\sigma_{95}=2 \times$ $\sqrt{\sigma_{\mathrm{BAU}}^{2}+\sigma_{R}^{2}}$, where $\sigma_{\mathrm{BAU}}^{2}$ and $\sigma_{R}^{2}$ are the variances calculated with the two climatic scenario runs
R30

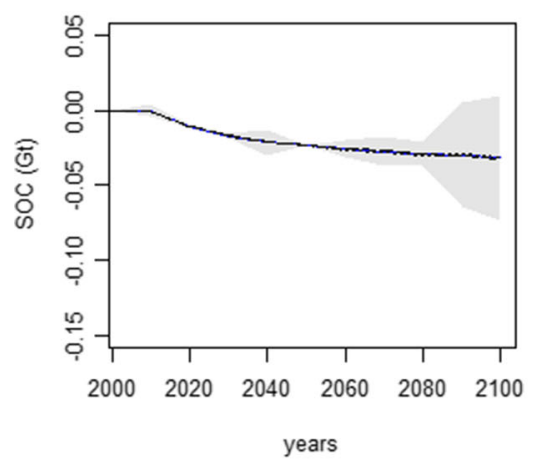

R90_C

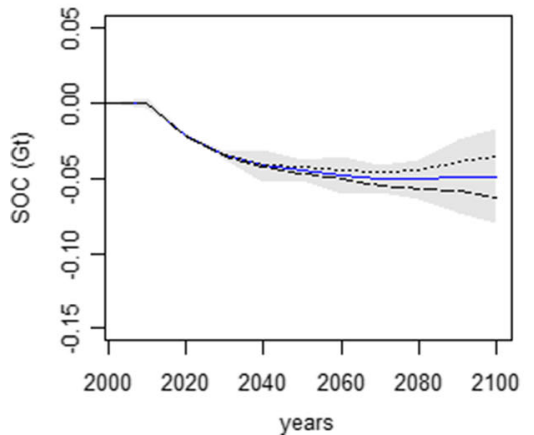

R90

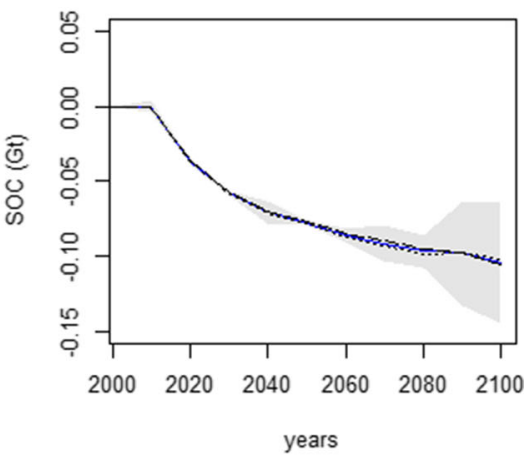

R90_B

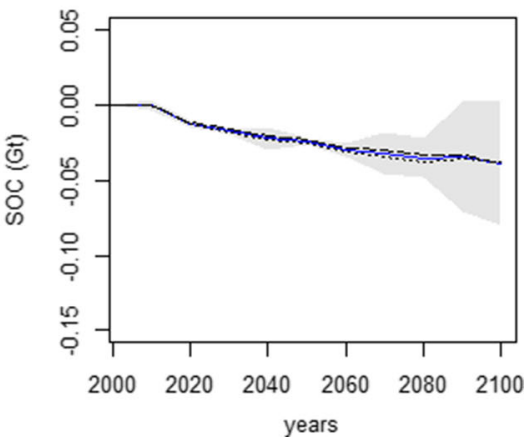

be considered in Member States accounting activities, thus offsetting the benefit of a higher share of renewable energy form biofuel.

Another important aspect is the implication on soil quality, which is one of the main components in EU CAP for the 2014-2020. Through the GAEC standards, soil erosion protection, soil structure maintenance and soil organic matter levels are recognised as minimum requirements to achieve a good condition of agricultural land [10]. It is recognized that residue cover strongly reduces water and wind erosion [31] and has an impact on nutrient cycling and SOC stock. In a short-term experiment, Blanco-Canqui and Lal [7] reported reduced SOC levels, decreased earthworm population, increased soil strength, reduced plant available water and decreased crop yields in certain soil type even when only $25 \%$ of maize residues were removed.

Small changes in total SOC have disproportionately large impacts on soil physical properties (aggregate stability, water infiltration rate, etc.) as reported by Powlson et al. [32]. In an 8-year field experiment, Stetson et al. [4] found that as the rate of residue removal increased, soil organic matter, wet aggregate stability, the $\mathrm{C} / \mathrm{N}$ ratio and microbial activity decreased significantly.

EU policies on biomass utilization must be coherent among energy, climate, agricultural and environmental frameworks. To reach this target, recommended management practices can be applied to prevent SOC decline and to balance the impact of straw removal [33, 34]. The effect of practices, including no-till cover crops, manure and compost application, and return of biofuel co-products were recently discussed by Blanco-Canqui [6]. The author concluded that, although these managements may partially or totally offset SOC losses, they are unlikely to replace all the SOC lost if residue is removed at excessive rates. Our results corroborate this view, since at the highest exportation rates (R90), the cover crop introduction and the biofuel co-product recycle still led to a net SOC loss at European level. The combination of different practices and moderate stover removal rates is likely the best solutions to increase the sustainability of bioenergy crops.

While European SOC estimations and scenario analysis with this modelling platform are quite robust [16, 35] some scenarios, such as the biodigestate return (R90_B), are very explorative. Short-term incubation experiments showed no impact of high-lignin fermentation by-product on crop yield [36], but long-term experiments are required to better understand long-term SOC dynamic, cropping system sustainability and better calibrate models.

\section{Conclusions}

The use of maize residue removal for biofuel production may be a promising strategy to increase the share of renewable energy in Europe. However, a coherent policy under a 


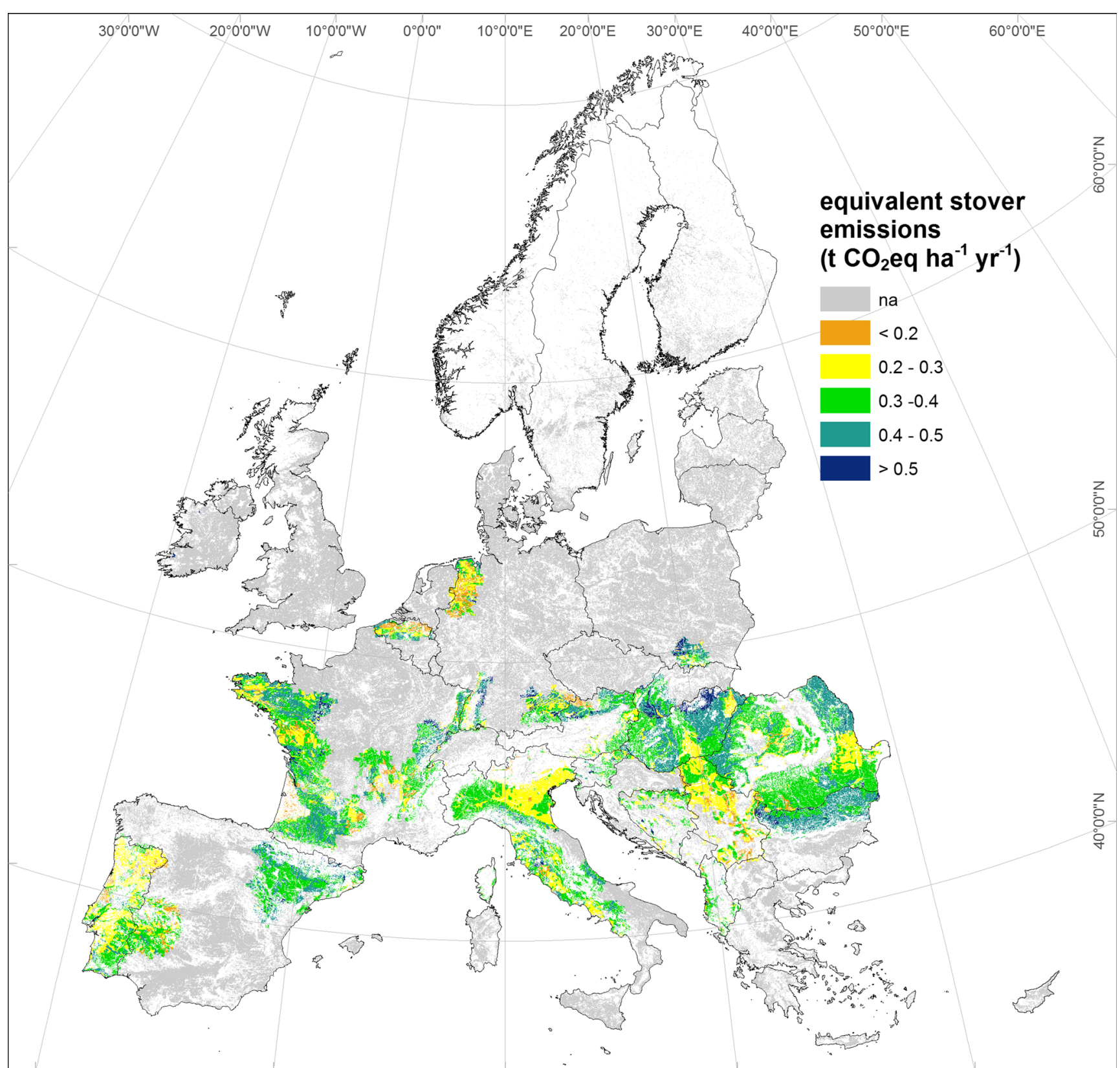

Fig. 5 Equivalent emissions $\left(\mathrm{t} \mathrm{CO}_{2}\right.$ eq. $\mathrm{ha}^{-1}$ year $^{-1}$ ) related to the alternative utilization (with respect to soil incorporation) of $1 \mathrm{tC}$ ha ${ }^{-1}$ of maize stover for bioethanol production, under the $\mathrm{R} 90$ scenario

common framework on sustainability must take into account all the environmental implications, such as those related to SOC depletion. Excessive rates of stover removal will affect both the soil ecosystem services and GHG savings, with net $\mathrm{CO}_{2}$ losses that should be accounted for by Member States in the next mandatory accounting period for grassland and cropland management. Moderate removal rates and the adoption of best management practices appear to be the most recommendable practices to increase the sustainability of bioenergy crops.

Considering that GHG saving at EU level must be $50 \%$ compared with fossil fuel by 2017 , it is important to estimate net SOC emissions and to compensate negative balances. The possibilities to design the best cropping system are numerous and strongly dependent on local pedo-climatic and management conditions. Therefore, the modelling platform described here can be a cost-effective tool to help policymakers in implementing the most sustainable bioenergy cropping systems.

Acknowledgments This paper is based on work carried out as preparation to support to the European Commission DG Agriculture's CAPRESE-SOILS project (CArbon PREservation and SEquestration in agricultural soils: options and implications for agricultural production). 
Open Access This article is distributed under the terms of the Creative Commons Attribution License which permits any use, distribution, and reproduction in any medium, provided the original author(s) and the source are credited.

\section{References}

1. EC 2010 (COM (2010) 265 final). Analysis of options to move beyond $20 \%$ greenhouse gas emission reductions and assessing the risk of carbon leakage. European Commission, Brussels

2. Ozdemir ED, Hardtlein M, Eltrop L (2009) Land substitution effects of biofuel side products and implications on the land area requirement for EU 2020 biofuel targets. Energy Policy 37:2986-2996

3. Don A, Osborne B, Hastings A, Skiba U, Carter MS, Drewer J et al (2012) Land-use change to bioenergy production in Europe: implications for the greenhouse gas balance and soil carbon. Glob Chang Biol Bioenergy 4(4):372-391

4. Stetson SJ, Osborn SL, Schumacher TE, Eynard A, Chilom G, Rice J, Nichols KA, Pikul JL Jr (2012) Corn residue removal impact on topsoil organic carbon in a corn-soybean rotation. Soil Sci Soc Am J 76(4):1399-1406

5. Anderson-Teixeira KJ, Davis SC, Masters MD, Delucia EH (2009) Changes in soil organic carbon under biofuel crops. Glob Chang Biol Bioenergy 1:75-96

6. Blanco-Canqui H (2013) Crop residue removal for bioenergy reduces soil carbon pools: how can we offset carbon losses? Bioenergy Res 6(1):358-371

7. Blanco-Canqui H, Lal R (2007) Soil and crop response to harvesting corn residues for biofuel production. Geoderma 141(3-4):355-362

8. Kochsiek AE, Knops JMH (2012) Maize cellulosic biofuels: soil carbon loss can be a hidden cost of residue removal. Glob Chang Biol Bioenergy 4(2):229-233

9. Kludze H, Deen B, Weersink A, van Acker R, Janovicek K, De Laporte A, McDonald I (2013) Estimating sustainable crop residue removal rates and costs based on soil organic matter dynamics and rotational complexity. Biomass Bioenergy 56:607-618

10. EC (2009) (EC No 73\2009) Council regulation establishing common rules for direct support schemes for farmers under the common agricultural policy and establishing certain support schemes for farmers, amending Regulations (EC) No. 1290/2005, (EC) No. 247/ 2006, (EC) No. 378/2007 and repealing Regulation (EC) No. $1782 / 2003$. Official Journal of the European Union, Brussels.

11. Huggins DR, Kruger CE, Painter KM, Uberuaga DP (2014) Sitespecific trade-offs of harvesting cereal residues as biofuel feedstocks in dryland annual cropping systems of the Pacific Northwest, USA. Bioenergy Res 7(2):598-608

12. Kumar K, Goh KM (1999) Crop residues and management practices: effects on soil quality, soil nitrogen dynamics, crop yield, and nitrogen recovery. Adv Agron 68(C):197-319

13. EC (2014) (COM (2014) 15 final). Communication from the commission to the European parliament, the council, the European economic and social committee and the committee of the regions. A policy framework for climate and energy in the period from 2020 to 2030. Official Journal of the European Union, Brussels

14. Surendran Nair S, Kang S, Zhang X, Miguez FE, Izaurralde RC, Post WM et al (2012) Bioenergy crop models: descriptions, data requirements, and future challenges. Glob Chang Biol Bioenergy 4(6):620-633

15. Smith WN, Grant BB, Campbell CA, McConkey BG, Desjardins RL, Kröbel R, Malhi SS (2012) Crop residue removal effects on soil carbon: measured and inter-model comparisons. Agric Ecosyst Environ 161:27-38

16. Lugato E, Panagos P, Bampa F, Jones A, Montanarella L (2014) A new baseline of organic carbon stock in European agricultural soils using a modelling approach. Global Chang Biol 20(1):313-326
17. Parton WJ, Stewart JWB, Cole CV (1988) Dynamics of C, N, P and S in grassland soils: a model. Biogeochemistry 5:109-131

18. Lugato E, Paustian K, Giardini L (2007) Modelling soil organic carbon dynamics in two long-term experiments of north-eastern Italy. Agric Ecosyst Environ 120:423-432

19. Lugato E, Berti A, Giardini L (2006) Soil organic carbon (SOC) dynamics with and without residue incorporation in relation to different nitrogen fertilisation rates. Geoderma 135:315-321

20. Panagos P, Van Liedekerke M, Jones A et al (2012) European soil data centre: response to European policy support and public data requirements. Land Use Policy 29:329-338

21. Rawls WJ, Brakensiek CL, Saxton KE (1982) Estimation of soil water properties. Trans Am Soc Agric Eng 25(1316-1320):1328

22. Mitchell TD, Carter TR, Jones PD et al (2004) A comprehensive set of high-resolution grids of monthly climate for Europe and the globe: the observed record (1901-2000) and 16 scenarios (2001-2100). Tyndall Centre for Climate Change Research, University of East Anglia, Norwich

23. Nakicenovic N, Alcamo J, Davis G et al (2000) Special report on emissions scenarios: a special report of working group III of the intergovernmental panel on climate change. Cambridge University Press, Cambridge

24. Johnson JMF, Reicosky D, Sharratt B, Lindstrom M, Voorhees W, Carpenter-Boggs L (2004) Characterization of soil amended with the by-product of corn stover fermentation. Soil Sci Soc Am J 68(1): 139-147

25. Whittaker C, Borrion AL, Newnes L, McManus M (2014) The renewable energy directive and cereal residues. Appl Energy 122: 207-215

26. Kim S, Dale BE (2005) Environmental aspects of ethanol derived from no-tilled corn grain: nonrenewable energy consumption and greenhouse gas emissions. Biomass Bioenergy 28(5):475-489

27. Spatari S, Zhang Y, Maclean HL (2005) Life cycle assessment of switchgrass- and corn stover-derived ethanol-fueled automobiles. Environ Sci Technol 39(24):9750-9758

28. Whitman T, Yanni SF, Whalen JK (2011) Life cycle assessment of corn stover production for cellulosic ethanol in Quebec. Can J Soil Sci 91(6):997-1012

29. Liska AJ, Yang H, Milner M et al (2014) Biofuels from crop residue can reduce soil carbon and increase $\mathrm{CO}_{2}$ emissions. Nat Clim Chang $4: 398-401$

30. EC (2013) Decision No. 529/2013/EU of the European Parliament and of the Council of 21 May 2013 on accounting rules on greenhouse gas emissions and removals resulting from activities relating to land use, land-use change and forestry and on information concerning actions relating to those activities. Official Journal of the European Union, Brussels

31. Bonner IJ, Muth DJ Jr, Koch JB, Karlen DL (2014) Modeled impacts of cover crops and vegetative barriers on corn stover availability and soil quality. Bioenergy Res 7(2):1-14

32. Powlson DS, Glendining MJ, Coleman K et al (2011) Implications for soil properties of removing cereal straw: results from long-term studies. Agron J 103:279-287

33. Xue X, Pang Y, Landis AE (2014) Evaluating agricultural management practices to improve the environmental footprint of cornderived ethanol. Renew Energy 66:454-460

34. Krasuska E, Faber A, Pudełko R, Jarosz Z, Borzecka-Walker M, Kozyra J, Syp A (2013) Emission saving opportunities for corn cultivation for ethanol in Poland. J Food Agric Environ 11(3-4):2050-2053

35. Lugato E, Bampa F, Panagos P, Montanarella L, Jones A (2014) Potential carbon sequestration of European arable soils estimated by modelling a comprehensive set of management practices. Global Change Biol. doi: 10.1111/gcb.12551.

36. Johnson JMF, Sharratt BS, Reicosky DC, Lindstrom M (2007) Impact of high-lignin fermentation byproduct on soils with contrasting organic carbon content. Soil Sci Soc Am J 71(4):1151-1159 